\title{
G

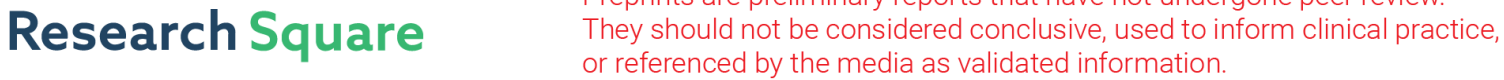 \\ Perimeter Confinements of Basic Health Zones and COVID-19 Incidence in Madrid, Spain
}

\section{García-García David}

Centro de Investigación Biomédica en Red de Epidemiología y Salud Pública

\section{Herranz-Hernandez Rafael}

Hospital Clínico San Carlos

\section{Rojas-Benedicto Ayelén}

Centro de Investigación Biomédica en Red de Epidemiología y Salud Pública

\section{León-Gomez Inmaculada}

Instituto de Salud Carlos III

\section{Larrauri Amparo}

Instituto de Salud Carlos III

\section{Peñuelas Marina}

Instituto de Salud Carlos III

\section{Guerrero-Vadillo Maria}

Instituto de Salud Carlos III

\section{Ramis Rebeca}

Instituto de Salud Carlos III

Gomez-Barroso Diana ( $\boldsymbol{\nabla}$ dgomez@isciii.es )

Instituto de Salud Carlos III

\section{Research Article}

Keywords: Covid-19, Madrid, Spain, perimeter closures

Posted Date: July 1st, 2021

DOl: https://doi.org/10.21203/rs.3.rs-646779/v1

License: (c) (i) This work is licensed under a Creative Commons Attribution 4.0 International License.

Read Full License

Version of Record: A version of this preprint was published at BMC Public Health on February 3rd, 2022. See the published version at https://doi.org/10.1186/s12889-022-12626-x. 


\section{Abstract}

Background: A unique policy of perimeter closures of Basic Health Zones (small administrative health units) was implemented in the Autonomous Region of Madrid from September $21^{\text {st }} 2020$ to May $23^{\text {rd }}$ 2021 to face the COVID-19 pandemic.

Aim: To assess the impact of local perimeter confinements on the 14-days cumulative incidence of SARSCoV-2 during the second wave of the pandemic in Madrid, Spain.

Methods: We compare the errors in estimation of two families of mathematical models: ones that include the perimeter closures as explanatory covariables and ones that do not, in search of a significant improvement in estimation of one family over the other. We incorporate leave-one-out cross-validation and the choice of the best over 15 models at each step in our analysis for statistical signification.

Results: The two families of models provided very similar estimations (correlation of the errors $>0.95$ $\left( \pm 10^{-3} 95 \% \mathrm{Cl}\right)$, difference in means of the errors $<1.2( \pm 0.795 \% \mathrm{Cl}) 14$-days cumulative incidence), both for a 2 weeks and 3 weeks delay in observed cumulative incidence and also when restricting the analysis to only those Basic Health Zones that were subject to at least one closure during the time under study.

Conclusion: Our analysis suggests that the perimeter closures by Basic Health Zone did not have a significant effect on the epidemic curve in Madrid, either 2 or 3 weeks after their activation.

\section{Background}

On March $14^{\text {th }} 2020$ the Spanish government issued the Royal Decree 463/2020, declaring the state of emergency throughout the Spanish territory. This was the starting point of the battery of Non Pharmaceutical Interventions aimed to tackle the global COVID-19 pandemic in Spain. These measures involved limiting people's mobility, restoration and commercial closures, capacity restrictions, cleaning protocols...; and they were uniform throughout the whole country for the duration of the state of emergency.

After two months, with the order SND/399/2020 [1] on May $9^{\text {th }}$, the easing of certain nationwide restrictions began, and phase 1 of the Plan for the de-escalation protocol started [2]. However, this plan was not applied uniformly to the whole country, with each Autonomous Community transitioning from one phase to another according to its epidemiological situation. Some measures continued to be nationwide, such as order SND/422/2020 [3], issued on May $19^{\text {th }}$, which regulated the mandatory use of masks. On June $7^{\text {th }}$, the Autonomous Regions recovered their authority to withdraw some of the measures established at the beginning of the state of emergency [4], as long as they had successfully gone through the de-escalation phases. The state of emergency ended on June $21^{\text {st }}$, with mobility being restored throughout Spain and the Autonomous Regions regaining full authority over public health measures. From October $25^{\text {th }} 2020$ to May $9^{\text {th }} 2021$, a new state of emergency was activated, 
encompassing similar Non Pharmaceutical Interventions to face the rise of incidence of COVID-19 [5]. This time the Autonomous Regions were in charge and measures differed between them, although following common guidelines given by the national government

Basic Health Zones (BHZs) are the smallest geographical sanitary areas in Spain [6, 7]. The Autonomous Community of Madrid, in addition to other measures applicable to its entire territory, designed a system of confinements by Basic Health Zone (BHZ), unique in Europe, activated depending on the registered cumulative incidence of COVID-19 cases. This policy began on September $21^{\text {st }} 2020$ and it was maintained until May $23^{\text {rd }}, 2021$. For this unique measure, the evaluation of its impact on the incidence values of the disease is of great importance.

The aim of this study was to examine the impact of this unique system of perimeter confinements by $\mathrm{BHZ}$ applied at the Autonomous Region of Madrid. We focused on the second wave of the COVID-19 pandemic (September $21^{\text {st }}$ to December $20^{\text {th }}$ ), to isolate the effect of this policy from the start of the vaccination process in Spain, on December $27^{\text {th }}$.

\section{Material And Methods}

\section{Study area}

The Autonomous Community of Madrid is divided into $286 \mathrm{BHZs}$ (Figure 1). The total population in Madrid on January $1^{\text {st }} 2020$ was 6.663 .394 inhabitants according to the National Statistics Institute of Spain official database [8].

\section{Perimeter confinements of $B H Z$ s}

The perimeter closures limited non-essential mobility from and to the BHZs involved, as well as nonessential activities within the BHZ. Exceptions to this restrictions included work-related mobility, access to educational centers, medical visits and other emergencies [9]. The already present restrictions at regional level were also made stricter at those BHZs with an active perimeter confinement, including curfews, limited seating capacities at restaurant premises, and other general measures intended to constrain the maximum number of people at public gatherings.

The information concerning which BHZs were confined at each point during the time of study was obtained from the Autonomous Community of Madrid's historic public repository [9], together with the threshold that triggered the closure of a given $\mathrm{BHZ}$, which changed over time (see Discussion).

\section{Covid-19 cases}

The weekly 14 days cumulative incidence $(\mathrm{Cl})$ rates per 100000 inhabitants at $\mathrm{BHZ}$ level were obtained from the open COVID-19 portal dataset of the Madrid Community Government [10] (Download February $\left.1^{\text {st }}\right)$. 
We assessed whether the perimeter confinements of $\mathrm{BHZs}$ had a significant impact on the 14 days $\mathrm{Cl}$ using Generalized Additive Models (GAMs) [11] as follows. We left out the data (cases and perimeter confinements) associated to one of the BHZs, and fitted two families of models to the resulting dataset. The models in the first family explained the 14 days $\mathrm{Cl}$ in terms of time, and the models in the second family explained the 14 days $\mathrm{Cl}$ in terms of time and the perimeter confinements of the BHZs. Within each of the two families of models, several parameters were tuned differently (type and number of basis functions), in search for the best fit possible, comprising 15 models in total. We then chose the best model in AIC score from each of the families, using them to estimate the 14 days $\mathrm{Cl}$ of the $\mathrm{BHZ}$ that was left out, and stored the absolute values of the errors. This procedure was repeated once for every $\mathrm{BHZ}$, so that every time a different $\mathrm{BHZ}$ was left out of the fitting process, resulting in two sets of errors in estimation (each one associated to each of the families of models). Finally, we searched for statistically significant differences in these two sets of errors with a Pearson's product-moment correlation test and a paired TOST [12], looking for possible consistent improvements in estimation for one family of models over the other. We performed this procedure with a time lag of 2 weeks and 3 weeks in the observed $\mathrm{Cl}$. Additionally, in order to magnify the possible differences, we repeated the whole process restricting the dataset to only those BHZs that were confined for at least one week during the time under study.

\section{Results}

\section{Perimeter confinements of $B H Z$ s}

Basic Health Zones are administrative health areas of the territory, with 22,752 inhabitants in average $(\min =2,615, \max =59,932)$ and spanning $28 \mathrm{~km}^{2}$ in average $\left(\min =0.19 \mathrm{~km}^{2}, \max =519 \mathrm{~km}^{2}\right)$. Large urban territories usually enclose several $\mathrm{BHZs}$, while in rural areas a single $\mathrm{BHZ}$ may comprise several municipalities.

Figure 1 shows the spatial distribution of the $286 \mathrm{BHZs}$ in Madrid, and in the site http://depifdd.isciiides.es:8080/restricMadrid/ we display the evolution in space and time of closures together with the cumulative incidence. The number of closed zones was heterogeneous, taking into account the different thresholds used and the evolution of the epidemic (see figure 2). A total of $81 \mathrm{BHZs}$ were confined for at least one week during the time period under study with an average of 0.29 closed weeks per $\mathrm{BHZ}$ among these from the total of 13 weekly observations per $\mathrm{BHZ}$. During this time span, the average 14 days $\mathrm{Cl}$ per $\mathrm{BHZ}$ reached 387.15 cases, rising to 476.45 when considering only those $\mathrm{BHZs}$ that have been perimeter confined for at least one week during this period, with a maximum recorded incidence of 1883.1 .

Table 1 shows the results of a Pearson's product-moment correlation test and a paired TOST test for equivalence for the two sets of errors obtained with the statistical models. We find very high correlations and negligible differences in means between the two sets. These results were consistent when 
considering either 2 or 3 weeks of lag in the observed $\mathrm{Cl}$, and also when restricting the analysis to only those $\mathrm{BHZs}$ that were closed for at least one week.

\begin{tabular}{|llll|}
\hline Statistical test & $\begin{array}{l}\text { Weeks } \\
\text { of lag }\end{array}$ & All BHZs & $\begin{array}{l}\text { BHZs that have been } \\
\text { closed at least once }\end{array}$ \\
\hline $\begin{array}{l}\text { Pearson's product-moment } \\
\text { correlation test }\end{array}$ & 2 & $\begin{array}{l}\text { Correlation: } 0.95\left( \pm 10^{-3}\right. \\
95 \% \mathrm{Cl})\end{array}$ & $\begin{array}{l}\text { Correlation: } 0.98\left( \pm 10^{-3} 95 \%\right. \\
\text { Cl })\end{array}$ \\
\cline { 2 - 4 } & 3 & $\begin{array}{l}\text { Correlation: } 0.99\left( \pm 10^{-3}\right. \\
95 \% \mathrm{Cl})\end{array}$ & $\begin{array}{l}\text { Correlation: } 0.99\left( \pm 10^{-5} 95 \%\right. \\
\mathrm{Cl})\end{array}$ \\
\hline Paired TOST & 2 & $\begin{array}{l}\text { Mean of differences: } 1.11 \\
( \pm 0.6295 \% \mathrm{Cl})\end{array}$ & $\begin{array}{l}\text { Mean of differences: } 0.26 \\
( \pm 0.8495 \% \mathrm{Cl})\end{array}$ \\
\hline 3 & $\begin{array}{l}\text { Mean of differences: } 0.36 \\
( \pm 0.395 \% \mathrm{Cl})\end{array}$ & $\begin{array}{l}\text { Mean of differences: } 0.13 \\
( \pm 0.0295 \% \mathrm{Cl})\end{array}$ \\
\hline
\end{tabular}

Table 1. Correlation and difference in means tests for the two sets of errors obtained from the analysis.

\section{Discussion}

This study evaluates the impact of the local perimeter confinements implemented during the second wave of COVID-19 in Madrid. This autonomous region adapted a special model of public health measures based on perimeter closures by $\mathrm{BHZ}$ depending of the epidemiological situation across time. Our results showed that there were no statistical differences in cumulative incidence between $\mathrm{BHZs}$ with perimeter closure and those without it.

In Spain, the universal use of masks (indoors and outdoors) is mandatory throughout the whole territory since May $19^{\text {th }} 2020$ [3]. On October $25^{\text {th }}$, the second state of emergency started and additional public health measures were implemented, with a range of normatives that varied across the autonomous regions. These included curfews (set at 23:00 in Madrid), limited seating capacities at restaurant premises and gathering limitations (maximum of 6 people in outdoors restaurant facilities and in-house meetings, and 4 people in indoors restaurant facilities in Madrid), and other general restrictions [13]. Prior to the state of emergency, the Government of Madrid implemented the strategy of perimeter confinements by $\mathrm{BHZ}$, in contrast to other Autonomous Regions which focused on local closures at municipality level (Galicia [14], Cantabria [15], among others). The epidemiological threshold triggering the closures changed during the study period. On September $21^{\text {st }}$, weekly BHZ perimeter confinements were activated at those $\mathrm{BHZs}$ where the 14 days cumulative incidence surpassed the 1.000 cases per 100.000 inhabitants. This threshold was decreased to 750 cases on October $12^{\text {th }}, 500$ cases on October $26^{\text {th }}$, and 400 cases on November $23^{\text {rd }}[9]$.

We assessed whether the perimeter confinements of $\mathrm{BHZs}$ had a significant influence on the evolution of the epidemic curve by modeling them as explanatory covariables in several mathematical models. We found that the estimations provided by the models that included the perimeter confinements as an 
explanatory variable and those that did not were statistically very similar, indicating that the perimeter confinements did not have a significant impact on the 14 days accumulated $\mathrm{Cl}$.

Several factors limit the effectiveness of the BHZ closures system. For example, due to the high permeability between neighboring BHZs and associated difficulty in the evaluation of the citizens' compliance to the measure, it has not been possible to determine if the policy was implemented effectively. In addition, a low risk perception towards the COVID-19 pandemic has been identified in the Spanish population during the time period under study [16].

While local mobility restrictions are effective in a theoretical modelling framework [17],[18], evidence suggests that an informed and coordinated approach is required for the effective implementation of such a response measure [19]. Being a rare policy, few studies that focus on the effect of such selective confinements of such small units as BHZs are available. Fotán-Vela et al. [20] also analyze the case of the $\mathrm{BHZ}$ closures in Madrid. Their analysis shows that the decrease in the epidemic curve in Madrid started before the impact of the perimeter closures could be reflected. Other than Madrid, the only other context were a similar policy has been adopted is Chile, to our best knowledge. Cuadrado et al [21] and Li et al [22] study the local lockdowns active during the first wave of the COVID-19 pandemic in this country, obtaining, respectively, a reduction in effective reproductive number (with a wide confidence interval, nevertheless), and a highly variable effectiveness of the policy (depending on duration of intervention and spillover effect from neighboring areas).

\section{Limitations of the analysis}

The average $\mathrm{BHZ}$ is an epidemiologically small unit, both in terms of population (22.750 inhabitants) and area $\left(28 \mathrm{~km}^{2}\right)$. Because of this, the usual joint point methods for trend analysis will presumably not reveal meaningful conclusions at local BHZ level, lacking statistical significance. This is the case as well for trend analysis on models that incorporate information from all the $\mathrm{BHZs}$, due to the asynchronicity in the implementation of the perimeter confinements among each of the BHZs. For the very same reason, precise estimations are not expected to be obtained from models fitted to this data. We thus chose to employ the present approach, sensible to general tendencies in models that have been adjusted differently. GAM models are expected to capture a greater influence of the additional explanatory variables included than trend analysis models [11], and we incorporated higher significance by a leaveone-out cross-validation process over the $286 \mathrm{BHZs}$ that involves the choice of the best of 15 models in each step.

An additional confounding effect is due to the fact that perimeter confinements (and COVID-19 related restrictions in general) have been introduced on an a posteriori basis. That is, restrictions are activated as a response to the increment of the 14 days $\mathrm{Cl}$, and therefore there is a natural correlation between $\mathrm{BHZs}$ with high $\mathrm{Cl}$ and perimeter confined $\mathrm{BHZs}$. An approach that does not focus on assessing the explicit, precise impact of these restrictions and rather on its statistical effect, such as ours, is thus preferred, as misleading associations may be inferred otherwise. 


\section{Conclusion}

Our analysis shows that the perimeter closures by $\mathrm{BHZ}$ do not have a significant effect on the epidemic curve in Madrid either 2 or 3 weeks after their activation.

\section{Declarations}

Ethics approval and consent to participate

Not applicable

Consent for publication

Not applicable

Availability of data and materials

The datasets generated and/or analysed during the current study are available in the public repository of the autonomous region of Madrid:

https://www.comunidad.madrid/servicios/salud/comunicados-covid-19-normativa-notasprensa\#repositorio-historico-medidas-adoptadas-crisis-sanitariaria.

https://datos.comunidad.madrid/catalogo/dataset/covid19_tia_zonas_basicas_salud.

Competing interests

no competing interest.

\section{Funding}

This research has been financed by Carlos III Health Institute (ISCIII) under the project COV20-00881. Authors' contributions

DGG and DGB, guided the preparation of the manuscript, conducted the analysis and drafted the first version. DGG, RR and ILG was responsible for providing technical and methodological support. ARB contributed with web application and maps. DGG conduct the statistical analysis. RHH was responsible to obtain the data (Covid-19 and legislation).MP,MGV and AL have contributed on conduct the discussion. All authors critically revised the manuscript and approved its final version.

\section{References}

1. Orden SND/399/2020, de 9 de mayo, para la flexibilización de determinadas restricciones de ámbito nacional, establecidas tras la declaración del estado de alarma en aplicación de la fase 1 del Plan para la 
transición hacia una nueva normalidad. https://www.boe.es/eli/es/o/2020/05/09/snd399/dof/spa/pdf. Accessed 22 Feb 2021.

2. Real Decreto-ley 21/2020, de 9 de junio, de medidas urgentes de prevención, contención y coordinación para hacer frente a la crisis sanitaria ocasionada por el COVID-19.

https://www.boe.es/buscar/pdf/2020/BOE-A-2020-5895-consolidado.pdf.

3. BOE.es - BOE-A-2020-5142 Orden SND/422/2020, de 19 de mayo, por la que se regulan las condiciones para el uso obligatorio de mascarilla durante la situación de crisis sanitaria ocasionada por el COVID-19. https://www.boe.es/eli/es/o/2020/05/19/snd422. Accessed 20 May 2021.

4. Real Decreto 555/2020, de 5 de junio, por el que se prorroga el estado de alarma declarado por el Real Decreto 463/2020, de 14 de marzo, por el que se declara el estado de alarma para la gestión de la situación de crisis sanitaria ocasionada por el COVID-19. https://www.boe.es/buscar/pdf/2020/BOE-A2020-5767-consolidado.pdf. Accessed 22 Feb 2021.

5. Real Decreto 926/2020, de 25 de octubre, por el que se declara el estado de alarma para contener la propagación de infecciones causadas por el SARSCoV-2.

https://www.boe.es/boe/dias/2020/10/25/pdfs/BOE-A-2020-12898.pdf. Accessed 22 Feb 2021.

6. Ministerio de Sanidad. Ordenación sanitaria del territorio en las Comunidades Autónomas. https://www.mscbs.gob.es/estadEstudios/estadisticas/docs/siap/Ordenacion_sanitaria_2019.pdf. Accessed 20 May 2021.

7. BOE.es - BOE-A-1984-2574 Real Decreto 137/1984, de 11 de enero, sobre estructuras básicas de salud. https://www.boe.es/buscar/doc.php?id=BOE-A-1984-2574. Accessed 3 Jun 2021.

8. Instituto Nacional de Estadística (INE). INEbase.

https://www.ine.es/dyngs/INEbase/listaoperaciones.htm.

9. Historic repository of COVID-19 related public health policies of the Autonomous Community of Madrid. https://www.comunidad.madrid/servicios/salud/comunicados-covid-19-normativa-notasprensa\#repositorio-historico-medidas-adoptadas-crisis-sanitariaria.

10. COVID-19 open data portal of the Autonomous Community of Madrid. https://datos.comunidad.madrid/catalogo/dataset/covid19_tia_zonas_basicas_salud.

11. Wood SN. Generalized Additive Models: An Introduction with R. Chapman and Hall/CRC; 2017. doi:10.1201/9781315370279.

12. Schuirmann DJ. A comparison of the Two One-Sided Tests Procedure and the Power Approach for assessing the equivalence of average bioavailability. Journal of Pharmacokinetics and Biopharmaceutics. 1987;15:657-80. doi:10.1007/BF01068419. 
13. BOCM - No 261. Sede Oficial del Boletín de la Comunidad de Madrid. http://www.bocm.es/boletincompleto/bocm-20201026/261/i.-comunidad-de-madrid/a\%29-disposiciones-generales/presidencia-dela-comunidad. Accessed 31 May 2021.

14. Orden del DOG n 223-Bis de 2020/11/4 - Xunta de Galicia.

https://www.xunta.gal/dog/Publicados/excepcional/2020/20201104/2476/AnuncioC3K1-0411202_es.html. Accessed 3 Jun 2021.

15. Boletín Oficial de Cantabria - Ultimo boletin publicado. https://boc.cantabria.es/boces/verBoletinExtraordinario.do?id=26162. Accessed 3 Jun 2021.

16. Rodríguez-Blázquez C, Romay-Barja M, Falcón M, Ayala A, Forjaz MJ. The COSMO-Spain Survey: Three First Rounds of the WHO Behavioral Insights Tool. Front Public Health. 2021;9. doi:10.3389/fpubh.2021.678926.

17. Chang S, Pierson E, Koh PW, Gerardin J, Redbird B, Grusky D, et al. Mobility network models of COVID19 explain inequities and inform reopening. Nature. 2021;589:82-7. doi:10.1038/s41586-020-2923-3.

18. Karatayev VA, Anand M, Bauch CT. Local lockdowns outperform global lockdown on the far side of the COVID-19 epidemic curve. PNAS. 2020;117:24575-80. doi:10.1073/pnas.2014385117.

19. Chowdhury R, Luhar S, Khan N, Choudhury SR, Matin I, Franco OH. Long-term strategies to control COVID-19 in low and middle-income countries: an options overview of community-based, nonpharmacological interventions. Eur J Epidemiol. 2020;35:743-8. doi:10.1007/s10654-020-00660-1.

20. Fontán-Vela M, Gullón P, Padilla-Bernáldez J. Selective perimeter lockdowns in Madrid: a way to bend the COVID-19 curve? Eur J Public Health. 2021.

21. Cuadrado C, Monsalves MJ, Gajardo J, Bertoglia MP, Nájera M, Alfaro T, et al. Impact of small-area lockdowns for the control of the COVID-19 pandemic. medRxiv. 2020;:2020.05.05.20092106. doi:10.1101/2020.05.05.20092106.

22. Li Y, Undurraga EA, Zubizarreta JR. Efficacy of Localized Lockdowns in the SARS-CoV-2 Pandemic. medRxiv. 2020;:2020.08.25.20182071. doi:10.1101/2020.08.25.20182071.

\section{Figures}




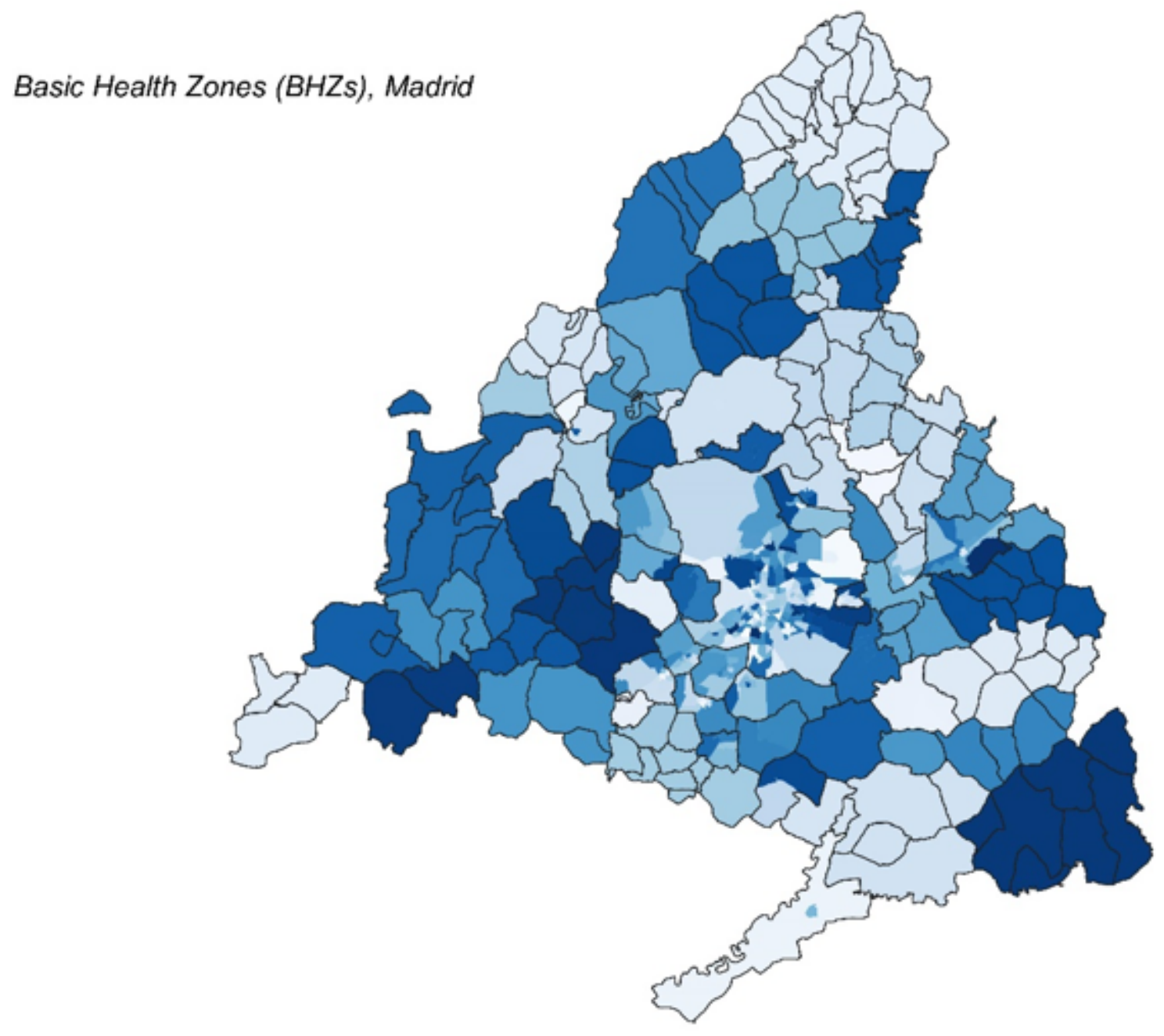

Figure 1

Spatial distribution of the Basic Health Zones (BHZs) in Autonomous Community of Madrid (in blue), and municipalities (black outline). 


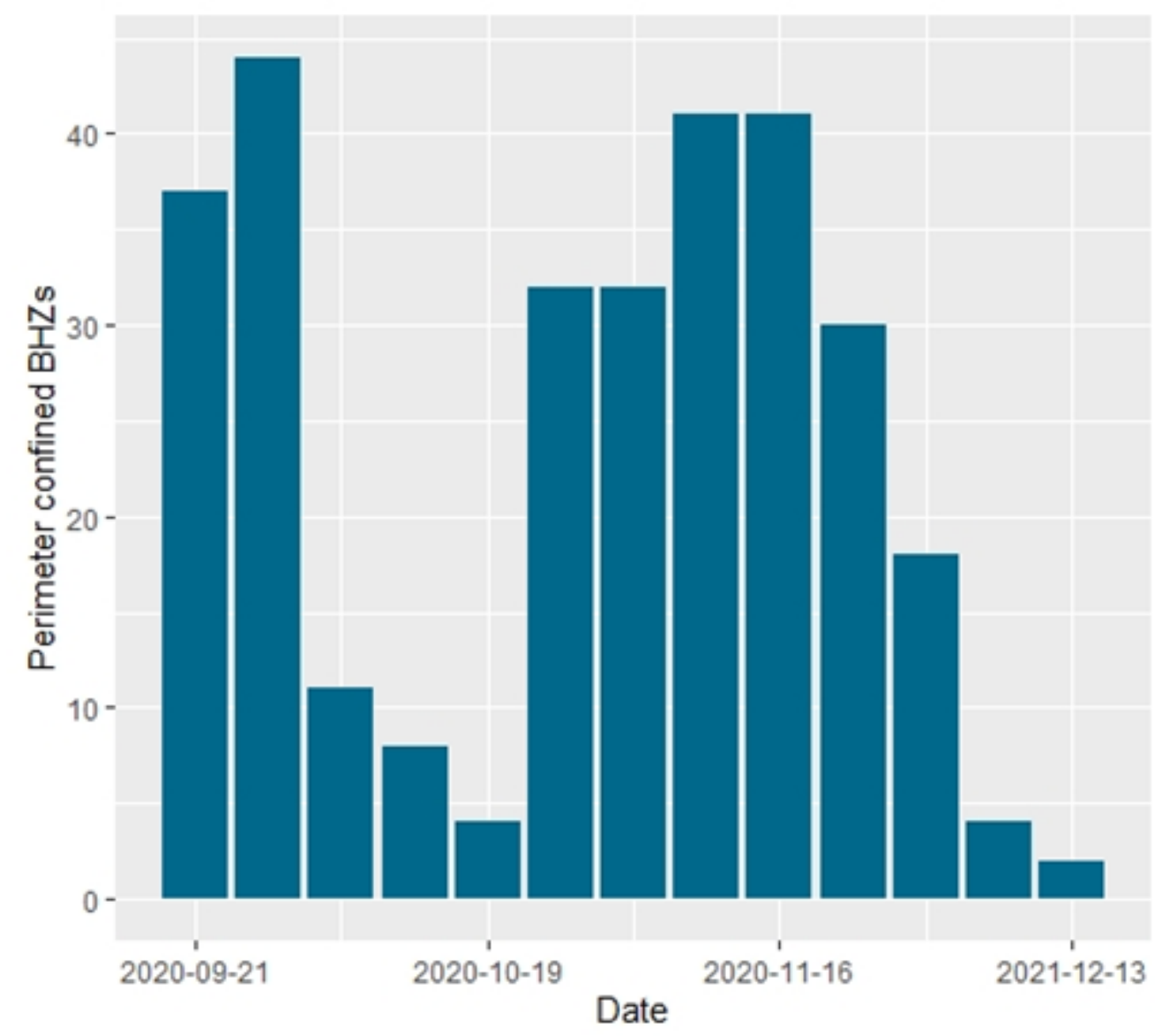

Figure 2

Total number of perimeter confined BHZs by date. 